University of South Florida

DIGITAL COMMONS

Digital Commons @ University of

@ UNIVERSITY OF SOUTH FLORIDA

South Florida

8-15-1998

\title{
El Nino Southern Oscillation-Related Ocean-Atmosphere Coupling in the Western Equatorial Pacific
}

\section{A. Mayer}

NOAA Atlantic Oceanographic and Meteorological Laboratory

Robert $\mathrm{H}$. Weisberg

University of South Florida, weisberg@marine.usf.edu

Follow this and additional works at: https://digitalcommons.usf.edu/msc_facpub

Part of the Marine Biology Commons

\section{Scholar Commons Citation}

Mayer, D. A. and Weisberg, Robert H., "El Nino Southern Oscillation-Related Ocean-Atmosphere Coupling in the Western Equatorial Pacific" (1998). Marine Science Faculty Publications. 120.

https://digitalcommons.usf.edu/msc_facpub/120

This Article is brought to you for free and open access by the College of Marine Science at Digital Commons @ University of South Florida. It has been accepted for inclusion in Marine Science Faculty Publications by an authorized administrator of Digital Commons @ University of South Florida. For more information, please contact digitalcommons@usf.edu. 


\title{
EI Niño-Southern Oscillation-related ocean-atmosphere coupling in the western equatorial Pacific
}

\author{
D. A. Mayer \\ Physical Oceanography Division, NOAA Atlantic Oceanographic and Meteorological Laboratory, Miami, Florida \\ R. H. Weisberg \\ Department of Marine Science, University of South Florida, St. Petersburg, Florida
}

\begin{abstract}
Using 43 years of Comprehensive Ocean-Atmosphere Data Set and related data for the period 1950-1992, an examination is made into the regional dependence of ocean-atmosphere coupling in relation to the El Niño-Southern Oscillation (ENSO). The cross correlation between sea surface temperature (SST) and sea level pressure (SLP) anomalies over the global tropics shows two patterns of significant negative correlation consistent with a local hydrostatic response of SLP to SST: (1) the eastern Pacific, where the correlation is symmetric about and largest on the equator, and (2) the western Pacific, where symmetric regions of negative correlation are found off the equator, separated by a region of positive correlation on the equator. Anomalies within these two patterns vary out of phase with each other. While the SLP anomalies on both sides of the basin are of similar magnitude, the SST anomalies in the east are much larger than those in the west. Despite this disparity in the SST anomaly magnitudes between the eastern and western Pacific we argue that the ocean-atmosphere couplings in the western and west-central Pacific are important for ENSO. The off-equator SST anomalies in the west enhance the SLP anomalies there, and they appear to initiate easterly wind anomalies over the far western Pacific during the peak El Niño phase of ENSO. As these easterlies evolve, their effect upon the ocean tends to oppose that of the westerly wind anomalies found over the west-central Pacific. These competing effects suggest a mechanism that may contribute to coupled ocean-atmosphere system oscillations. The west-central equatorial Pacific (the region separating the eastern and western patterns), while exhibiting large momentum and heat flux exchanges, shows minimum correlation between SST and SLP. Thus neither the SST and SLP anomaly magnitudes nor the correlation between them is alone indicative of ocean-atmosphere coupling, and the regional dependence for such coupling in relation to ENSO appears to be more complicated than mechanistic interpretations of ENSO would suggest.
\end{abstract}

\section{Introduction}

Interannual climate anomalies occur on a global scale as a consequence of tropical ocean-atmosphere interactions associated with the El Niño-Southern Oscillation (ENSO) [e.g., Diaz and Markgraf, 1992]. Omitting continental heat sources, models of ENSO that are based upon the transfer of momentum and heat between the ocean and atmosphere have been interpreted in terms of two mechanisms: the delayed oscillator and the slow mode. The delayed oscillator mechanism [Suarez and Schopf, 1988; Battisti and Hirst, 1989] is attributed to coupling in the eastern Pacific that provides a positive feedback for anomaly growth. This is followed by a negative feedback that eventually reverses the anomalies through the effects of oceanic equatorial waves that propagate to, and reflect from, the western boundary. The slow-mode mechanism [Hirst, 1986, 1988 ] is attributed to a slowly propagating, wind-driven sequence of oceanic divergence and convergence that is uniformly coupled everywhere to the atmosphere via sea surface temperature (SST). Because these and other mechanisms dif-

Copyright 1998 by the American Geophysical Union.

Paper number $98 \mathrm{JC} 01464$.

0148-0227/98/98JC-01464\$09.00 fer on where coupling occurs, further understanding of ENSO requires improved descriptions of the regional dependence of the heat and momentum transfers that occur between the ocean and the atmosphere.

The present paper considers the observational basis for ENSO-related ocean-atmosphere coupling using the historical Comprehensive Ocean-Atmosphere Data Set (COADS) [Woodruff et al., 1987] data and SST derived from it [Smith et al., 1996]. We begin with the large-scale relationships between SST, sea level pressure (SLP), and surface winds. These relationships are central to understanding the workings of the ocean-atmosphere system in the tropics. Coupling between the ocean and the atmosphere is achieved by a sequence of positive and negative feedbacks that allow the system to oscillate. The atmosphere affects the ocean through surface wind stress (momentum flux), and the ocean affects the atmosphere through SST-induced heating (heat flux). Heat flux, in turn, affects SLP and hence the winds. By examining the interrelationships between these variables, inferences are drawn on the regional dependence of such couplings. We find that the exchanges of heat and momentum that are implied over the western Pacific suggest a mechanism for ENSO-like oscillations [Weisberg and Wang, 1997a, b] that differs from either the 

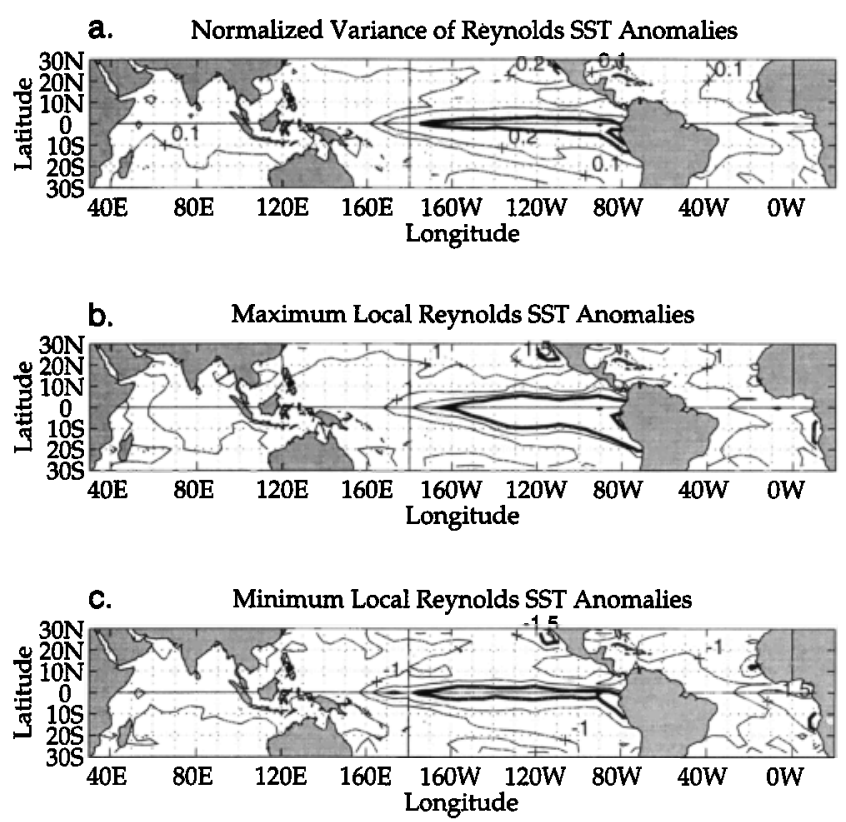

Figure 1. (a) Sea surface temperature (SST) anomaly field variance normalized by the maximum variance of $1.35\left({ }^{\circ} \mathrm{C}\right)^{2}$ located near $85^{\circ} \mathrm{W}, 4^{\circ} \mathrm{S}$. The contours are $0.1,0.2,0.5$ (bold), and 0.9 (bold). (b) Field of maximum SST anomalies with contours of 1, 1.5, 2 (bold), and 5 (bold). (c) Field of minimum SST anomalies with contours of -2 (bold) -1.5 , and -1 .

delayed oscillator or the slow-mode mechanisms. All of these mechanisms may be complementary, however, because they provide different feedbacks that enable the system to oscillate with each depending on coupling in different regions.

The paper is organized as follows. The data are introduced in section 2 . The analyses are presented in section 3 , beginning with descriptions of the interannual variability and the correlations between SST and SLP anomalies over the global tropics. The focus then shifts to the fields of SST, SLP, and surface wind anomalies in the tropical Pacific as a whole and the western Pacific separately, followed by a simple thermodynamic argument for the SST and SLP relationship that is found in the west. The pattern evolution is such that easterly (westerly) wind anomalies form over the far western Pacific during the time of peak El Niño (La Niña) warming (cooling) in the east. With the equatorial western Pacific zonal wind anomalies directed opposite to those in the central Pacific a negative feedback is achieved. Section 4 provides a summary and discussion.

\section{Data}

The analysis domain is a global strip extending from $30^{\circ} \mathrm{S}$ to $30^{\circ} \mathrm{N}$, within which the data spans a 43 year period (516 months) from 1950 through 1992. The enhanced Smith et al. [1996] data, partly derived from COADS, were used for SST owing to advantages over the original COADS as discussed by Enfield and Mayer [1997]. The monthly COADS data with a spatial resolution of $2^{\circ}$ latitude by $2^{\circ}$ longitude were used for SLP and vector wind components $(U, V)$. Three month running means were calculated after a bridging routine was used to fill temporal gaps. In cases where more than one month was missing the data were filled and smoothed as described by Mayer and Weisberg [1993]. All data were then rebinned into
747 boxes of dimension $4^{\circ}$ latitude by $6^{\circ}$ longitude. Finally, anomalies were computed by subtracting the 43 year monthly climatologies from these data. Unless stated otherwise, subsequent references to data relate to these anomalies.

\section{Analyses}

To provide a global context for tropical SST variability, a normalized SST variance field is given in Figure 1a, where the maximum variance $\left(1.35\left({ }^{\circ} \mathrm{C}\right)^{2}\right)$ is located off the South American coast near $4^{\circ} \mathrm{S}, 85^{\circ} \mathrm{W}$. Values $>0.5$ delineate the central and eastern equatorial Pacific Ocean where the ENSO-related SST anomalies are largest (ranging from $+5^{\circ}$ to $-3^{\circ} \mathrm{C}$ ). Although similar variance structures are also found in the eastern equatorial Atlantic Ocean, the variance levels in the Atlantic are smaller by roughly a factor of 3. Zebiak [1993] described both oceans as manifesting a "coupled mode signature," where SST correlates with meteorological variables.

Variance fields (being squared quantities) tend to underrepresent spatial scales. Another representation of the domain in which variability occurs is provided by the spatial distribution of SST maximum and minimum anomalies over the 43 year record length (Figures $1 \mathrm{~b}$ and $1 \mathrm{c}$, respectively). The principal regions of anomalous SST are delineated by values of $\pm 2{ }^{\circ} \mathrm{C}$ for maximum and minimum SST, respectively. There are five regions of maximum and minimum SST; one along the equator in the Pacific and the others both north and south of the equator along the western coasts of South America/Mexico and Africa. Ocean dynamical influences in these regions are distinguished by either equatorial or coastal upwelling. For the equator the maximum anomaly field has a broader meridional scale and extends farther southward in contrast to the minimum anomaly field that is symmetric about the equator (westward of $110^{\circ} \mathrm{W}$ ) and extends farther to the west. The smaller meridional and larger zonal scales for the minimum field, along with its concomitant equatorial symmetry, are consistent with equatorial upwelling as the source of the cold anomalies (except for the coastal anomalies attributed to coastal upwelling).

\subsection{Correlation Field}

A basic assessment of the relationship between the fields of SST and SLP is provided by their point by point unlagged correlation field, as shown for the global tropics in Plate 1a. Dividing these correlations by their corresponding standard errors [Sciremammano, 1979] results in the standardized correlation field of Plate $1 \mathrm{~b}$ in which values $>2.0$ exceed the $95 \%$ significance level (SL) for the null hypothesis. These correlation fields are based on anomalies with respect to the 43 year monthly climatologies. Despite the removal of the climatological annual cycle, time series variance remains up to the Nyquist frequency $\left(0.5\right.$ cycles month $\left.{ }^{-1}\right)$. To test the effect of high-frequency variance on the correlation patterns, the fields were recomputed after applying an 18 month low-pass filter (described below) to the SST and SLP data. No appreciable differences were found, demonstrating that the correlation patterns are the result of variability on interannual and longer timescales.

Although regions of significant negative and positive correlations are observed, only the regions of negative correlations are consistent with a hydrostatic relationship where cold (warm) SST gives rise to high (low) SLP [e.g., Lindzen and Nigam, 1987; Wallace et al., 1989]. These are found in roughly 


\section{a. Local Zero-Lag Crosscorrelation between Reynolds SST and SLP Anomalies}

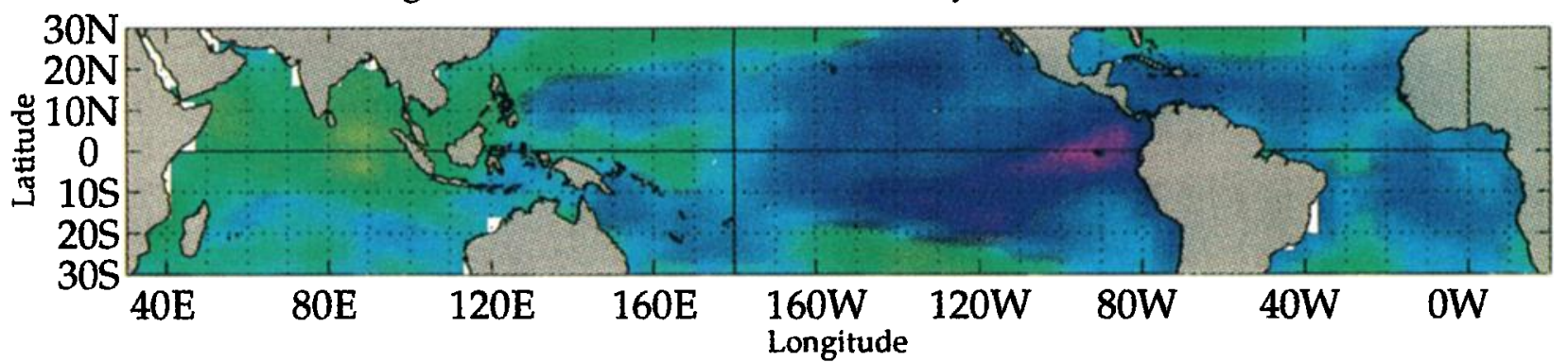

\begin{tabular}{llllllll|ll|l|}
\hline & & & & & & & & & & \\
-1 & -0.8 & -0.6 & -0.4 & -0.2 & 0 & 0.2 & 0.4 & 0.6 & 0.8 & 1
\end{tabular}

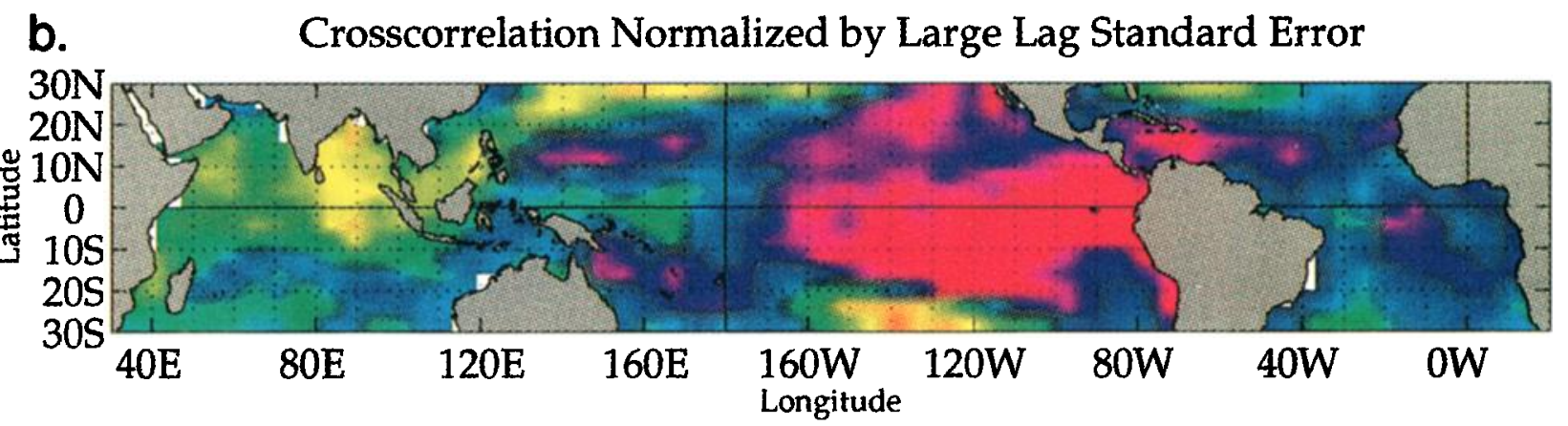

\begin{tabular}{|cccccccc|cc|c|}
\hline & & & & & & 1 & & 1 & & \\
-5 & -4 & -3 & -2 & -1 & 0 & 1 & 2 & 3 & 4 & 5
\end{tabular}

Plate 1. (a) The local, zero lag, cross-correlation field between SST and sea level pressure (SLP) in the global tropics. (b) Same as Plate 1a but normalized by the corresponding standard error field such that values $>2.0$ (2.7) exceed a significance level of $95 \%(99 \%)$. Degrees of freedom were determined by the integral timescale after Sciremammano [1979].

eight locations: (1) equatorial Atlantic, (2) western tropical North Atlantic [e.g., Knaff, 1997], (3) Caribbean, (4) northwest Africa coast, (5) eastern equatorial Pacific, (6) eastern tropical North Pacific, (7) western tropical South Pacific, and (8) western tropical North Pacific. While phase relationships between SST and SLP are not revealed by the unlagged correlations in Plate 1 , as will emerge below, the maximum correlations throughout the domain are generally associated with lags of no more than 1 or 2 months. Therefore a lag-maximum correlation analysis does not alter the patterns in Plate 1 . These patterns also result when using the original COADS data instead of the enhanced Smith et al. [1996] data.

The present paper will concentrate primarily on the eastern equatorial Pacific (EP), the western tropical South Pacific (WPS), and the western tropical North Pacific (WPN) regions. Positive correlations (of marginal significance) are found in the western equatorial Pacific region between WPS and WPN, which is part of the Tropical Ocean-Global Atmosphere (TOGA) Coupled Ocean-Atmosphere Response Experiment (COARE) area [Webster and Lukas, 1992]. Farther to the west, the South China Sea and the eastern Indian Ocean exhibit large, significant positive correlations. Interestingly then, the global domain along the equator is split between positive correlations over the eastern hemisphere and negative correla- tions over the western hemisphere. In the Pacific the regions west and east of the dateline are distinguished by off-equator patterns of negative correlations straddling positive correlations on the equator in the west versus negative correlations over the entire tropical domain in the east. The regions of maximum positive and negative correlations within the global tropics are the eastern Indian and the eastern Pacific Oceans, respectively.

To describe the temporal variability for regions of positive and negative correlations, areal indices for SST and SLP were computed by averaging over several ( $4^{\circ}$ latitude by $6^{\circ}$ longitude) boxes centered about the following locations: the eastern equatorial Pacific at $0^{\circ}, 97^{\circ} \mathrm{W}(\mathrm{EP})$, the western tropical South Pacific at $12^{\circ} \mathrm{S}, 152^{\circ} \mathrm{E}$ (WPS), and the western tropical North Pacific at $12^{\circ} \mathrm{N}, 143^{\circ} \mathrm{E}$ (WPN) for negative correlations and the eastern equatorial Indian Ocean at $0^{\circ}, 83^{\circ} \mathrm{E}$ and the western equatorial Pacific at $0^{\circ}, 161^{\circ} \mathrm{E}$ for positive correlations. These regional averages were then low-pass filtered with a 31-point Lanczos filter (providing reductions of 6 dbar at 18 months and 20 dbar at 12.5 months) and normalized to unit variance. The resulting indices are shown in Figure 2. With the exception of the western equatorial Pacific index (SL $<90 \%$ ) these indices come from regions where the SST and SLP correlations are highly significant (SL > 99\%). Eastern and western Pacific 


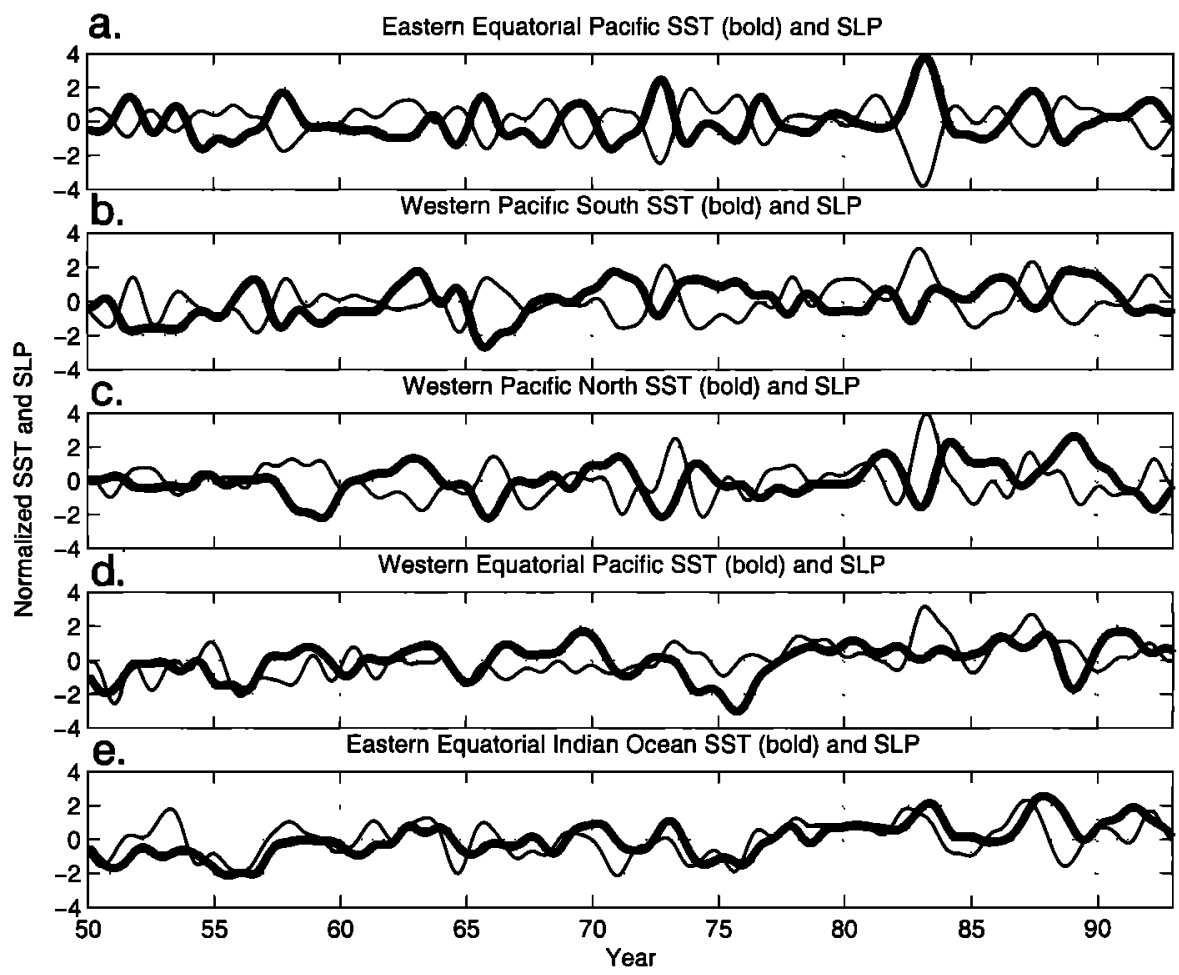

Figure 2. Areal indices of SST and SLP anomalies for five regions in the global tropics centered upon (a) the eastern equatorial Pacific (EP) at $0^{\circ}, 97^{\circ} \mathrm{W}$, (b) the western Pacific south of the equator (WPS) at $12^{\circ} \mathrm{S}$, $152^{\circ} \mathrm{E}$, (c) the western Pacific north of the equator (WPN) at $12^{\circ} \mathrm{N}, 143^{\circ} \mathrm{E}$, (d) the western equatorial Pacific at $0^{\circ}, 161^{\circ} \mathrm{E}$, and (e) the eastern equatorial Indian Ocean at $0^{\circ}, 83^{\circ} \mathrm{E}$. The indices are low-pass filtered (as given in the text) and normalized to unit standard deviation.

variability for SST and SLP is distinguished by comparing the variance of the EP index with the variances of the WPS and WPN indices. For SST the WPS and WPN variances are about an order of magnitude smaller than that for $\operatorname{EP}\left(0.12\left({ }^{\circ} \mathrm{C}\right)^{2}\right.$ and $0.06\left({ }^{\circ} \mathrm{C}\right)^{2}$ in the west, respectively, versus $0.75\left({ }^{\circ} \mathrm{C}\right)^{2}$ in the east). In contrast, for SLP the variances are comparable ( 0.7 and $0.5 \mathrm{mbar}^{2}$ in the west, respectively, versus $0.4 \mathrm{mbar}^{2}$ in the east).

The nature of the Plate 1 correlations becomes clearer upon inspection of Figure 2. The EP, WPS, and WPN indices are all indicative of ENSO. In each of these three regions, SST and SLP are essentially out of phase, which accounts for their negative correlations. At WPS and WPN, SLP lags SST by about a month, while at EP, there is no lag. The WPS and WPN indices are also anticorrelated with the EP indices. In contrast with the EP, WPS, and WPN indices, the equatorial western Pacific index, by virtue of marginal positive correlation, fails to exhibit regular ENSO behavior. In the eastern equatorial Indian Ocean the SST and SLP indices show large positive correlation, but with SST lagging SLP by several months. With respect to amplitudes, during the larger of the ENSO cycles the SLP anomalies at WPS and WPN approach 2 mbar, compared with 1 mbar in the eastern equatorial Indian Ocean, whereas the corresponding SST anomalies at these locations are between $0.5^{\circ} \mathrm{C}$ and $1^{\circ} \mathrm{C}$. Since the SLP anomalies tend to be in phase at these locations the larger values observed in the western Pacific Ocean suggest that this is the source region for the pressure gradient observed over the eastern Indian Ocean.

To further quantify the Figure 2 observations, lagged cross- correlation analyses were performed between the SST and SLP indices. For WPS and WPN, SLP lags SST by about 1 month (SL $>99 \%$ ) with correlation coefficients of $\rho=-0.42$ and -0.45 and regression coefficients of $r=1$ and $-1.3 \mathrm{mbar}$ ${ }^{\circ} \mathrm{C}^{-1}$, respectively. The negative correlation along with the 1 month lag suggests a causal relationship in these western $\mathrm{Pa}$ cific, off-equator regions. Elsewhere, SST and SLP vary either in phase, or SLP leads SST. For example, the EP indices correlate with $\rho=-0.84$, zero lag, and $r=-0.6 \mathrm{mbar}^{\circ} \mathrm{C}^{-1}$, and the eastern equatorial Indian Ocean indices correlate positively with SLP leading SST by 3 months (SL > 99\%).

Lagged cross-correlation analyses were also performed between regions. With regard to the SST indices in the Atlantic and eastern Pacific the results are consistent with Enfield and Mayer [1997], who showed that the equatorial Atlantic and the tropical North Atlantic indices vary independently and that the tropical North Atlantic index lags the eastern equatorial Pacific index by roughly 5 months (SL $>99 \%$ ).

As a summary of the Pacific findings, the SST anomalies at WPS lead all other indices with the SST anomalies at WPS leading those at EP by $\sim 1$ month. At WPN and WPS, (cold/ warm) SST anomalies lead (high/low) SLP anomalies by $\sim 1$ month, whereas at EP (cold/warm) SST anomalies occur in phase with (high/low) SLP anomalies.

\subsection{Principal Component Analysis for Pacific SST and SLP Anomalies}

Given the distinct patterns of correlation and the resultant indices just discussed, we further investigate the joint variability between the coupled patterns of SST and SLP and their 
a.

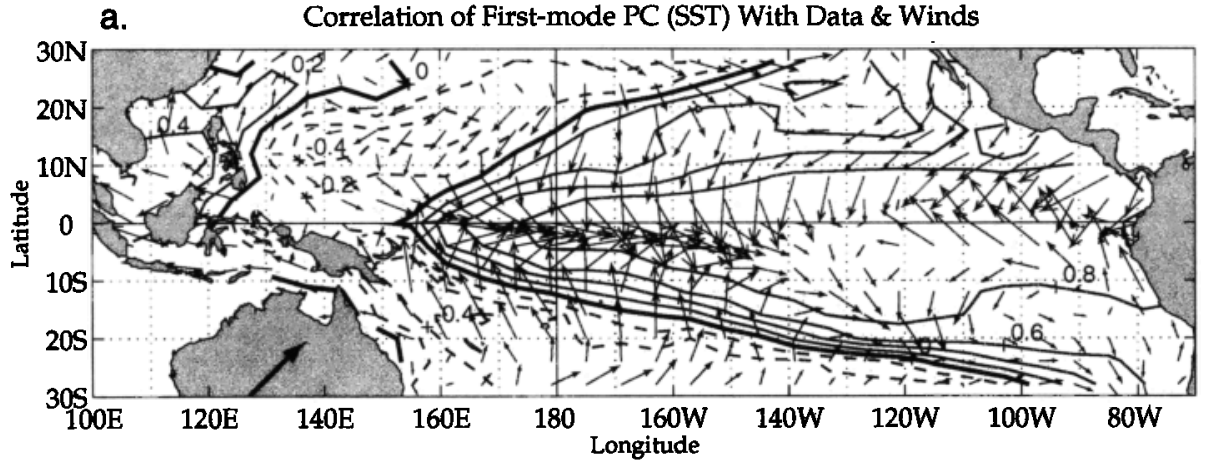

b.

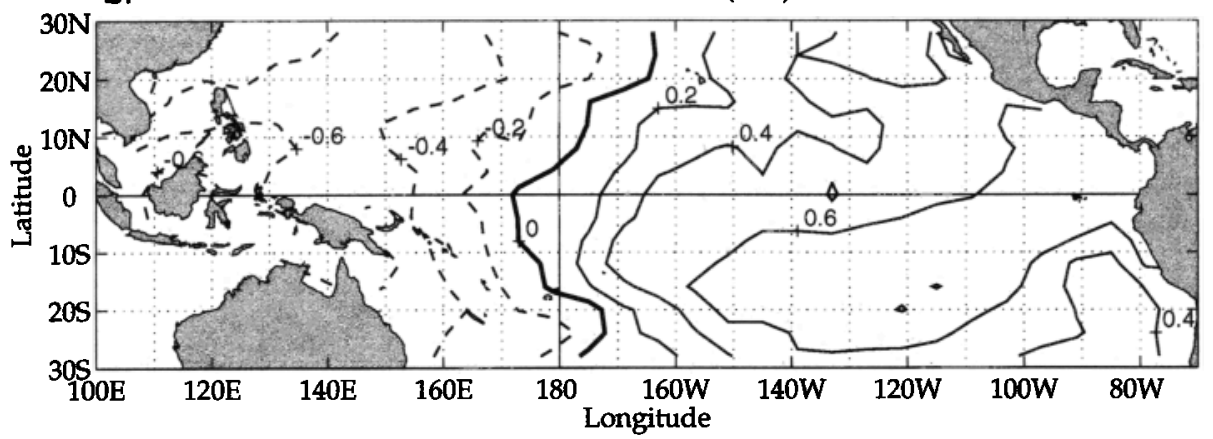

Figure 3. (a) The correlation fields between the first-mode principal component time series for SST and the SST and vector wind anomaly data. (b) The correlation field between the first-mode principal component time series for SLP and the SLP anomaly data. Figures 3a and $3 \mathrm{~b}$ are for the entire Pacific domain, and the contour intervals are 0.2 . The sign convention for the vector wind anomaly correlations is with respect to the El Niño warm phase of El Niño-Southern Oscillation (ENSO). Their direction reverses for the La Niña cold phase of ENSO. The bold vector shows the magnitude for a wind vector correlation of 0.5 .

relationships to the surface wind field. To concentrate the most information into the fewest number of objectively determined modes within regions evincing negative SST/SLP correlations (indicative of causality), the analyses are now limited to the tropical Pacific from $110^{\circ} \mathrm{E}$ to $70^{\circ} \mathrm{W}$ over the latitude band $30^{\circ} \mathrm{S}$ to $30^{\circ} \mathrm{N}$. Data are organized into $4114^{\circ}$ latitude by $6^{\circ}$ longitude boxes. A smaller domain for the western Pacific (WP) will also be considered separately, consisting of $794^{\circ}$ latitude by $6^{\circ}$ longitude boxes from $120^{\circ} \mathrm{E}$ to $160^{\circ} \mathrm{E}$ over the latitude band $20^{\circ} \mathrm{S}$ to $20^{\circ} \mathrm{N}$. The approach used, similar to that of Bretherton et al. [1992] and Wallace et al. [1992], consists of three parts: two autoanalyses (or single-field analyses) and a cross (or jointfield) analysis. The single-field analyses are standard empirical orthogonal functions (EOF). The joint field analyses are either singular-value decompositions (SVD) or canonical correlation analyses (CCA). A unified way of considering these methods is discussed in Appendix A.

For purposes of statistical inference, significance levels for correlations and mode separability, as discussed by North et al. [1982], are based upon normally distributed random variables with degrees of freedom determined from an integral independence time scale as given by Sciremammano [1979].

3.2.1. Results: Pacific region. As a representation of the large-scale variability over the tropical Pacific domain, the temporal correlation fields between the first-mode EOF for SST and the SST and vector wind data are shown in Figure 3a. Similarly, the temporal correlation field between the firstmode EOF for SLP and the SLP data is shown in Figure 3b. Squaring these correlation values yields the fraction of vari- ance locally accounted for by these modes. The correlation pattern for SST represents the spatial pattern of the principal El Niño ocean response. The temporal variability of this firstmode EOF for SST (T1) from which the correlation field is calculated is the same as that described by Enfield and Mayer [1997], and it is virtually identical to the NINO3 index (areal index of SST anomalies over the region $5^{\circ} \mathrm{S}-5^{\circ} \mathrm{N}, 90^{\circ} \mathrm{W}-$ $150^{\circ} \mathrm{W}$ ). The largest correlation between the data and $\mathrm{T} 1$ is centered about the equator to the east of the dateline with the meridional scale of this pattern increasing to the east. West of the dateline, the sign of the correlation reverses and offequator, negative correlation maxima occur between $10^{\circ}$ and $20^{\circ}$ from the equator. Superimposed upon this is the vector correlation field between $\mathrm{T} 1$ and the surface wind anomalies. The sign convention is such that the anomalous wind vector direction corresponds to the eastern Pacific warm phase of ENSO. Conversely, the vector wind direction is reversed during the cold phase of ENSO. The correlation pattern between the temporal variability of the first-mode EOF for SLP (P1) and the SLP data represents the Southern Oscillation, which is the atmospheric counterpart to the principal El Niño ocean response. The meridional scale of the $\mathrm{P} 1$ correlation pattern is broader than that for $\mathrm{T} 1$ with the zero correlation line or pivot point of the Southern Oscillation centered about the dateline. The highest positive correlation occurs over the eastern side of the basin and somewhat south of the equator, and the highest negative correlation occurs over the Indonesian archipelago.

Although only first-mode EOFs are shown, the first two modes of each field are separable in that there are no over- 
a.

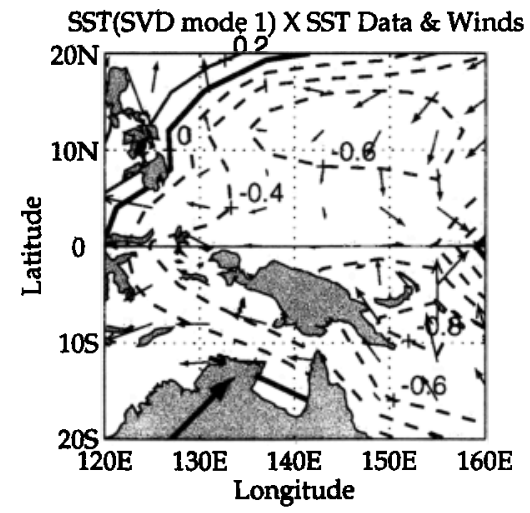

b. SST(SVD mode 2) $X$ SST Data \& Winds

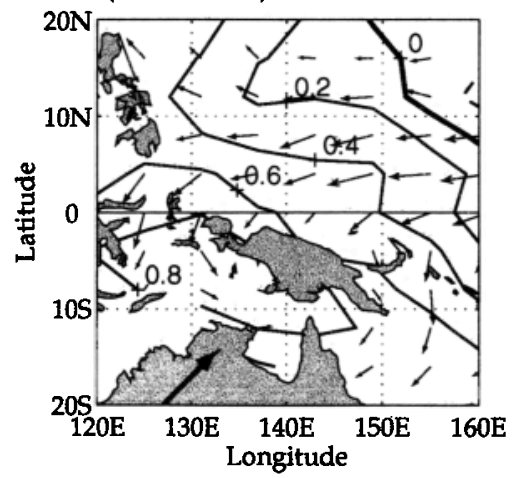

Figure 4. The correlation fields between the first-mode principal component time series for SST from the singular-valve decomposition (SVD) cross analysis between SST and SLP and the SST and vector wind anomaly data. (b) The correlation fields between the second-mode principal component time series for SST from the SVD cross analysis between SST and SLP and the SST and vector wind anomaly data. Figures $4 \mathrm{a}$ and $4 \mathrm{~b}$ are for the western Pacific domain, and the contour intervals are 0.2. The vector wind anomaly sign convention is as in Figure 3, and the bold vector shows the magnitude for a wind vector correlation of 0.5 .

lapping errors $\left(\delta \lambda_{i}\right)$ in the eigenvalues $\left(\lambda_{i}\right)$ where $\delta \lambda_{t}=$ $\pm \lambda_{2} \sqrt{2 / \eta}$ and $\eta$ is the number of degrees of freedom. The first-mode variances represent $52 \%$ of the total variance for SST and $21 \%$ for SLP.

The correlation pattern between SST and SLP in Plate 1 can be accounted for by these first-mode variances. First, as in Plate 1, the temporal cross correlation between $\mathrm{T} 1$ and $\mathrm{P} 1$ is maximum, $\rho=-0.88$ (SL $>99 \%$ ), at zero lag. Second, the difference in the way that negative and positive regions of correlation are organized in the eastern and western sides of the Pacific is determined by the difference in the spatial patterns for these SST and SLP modes. The Southern Oscillation, as seen in the SLP field of Figure 3, pivots about the dateline, whereas the SST response is more equatorially confined with positive values extending westward of the Southern Oscillation pivot point. Thus the SST/SLP correlation is negative everywhere in the tropics over the eastern side of the basin, whereas it tends to be positive on the equator west of the SLP pivot point. In contrast with this behavior on the equator, the firstmode correlation pattern for SST in the western Pacific shows off-equator maxima of opposite sign from that in the east. Since this change in sign off the equator is concomitant with the change in sign of the Southern Oscillation a negative correlation between off-equator SST and SLP is observed in the western Pacific. From these observations we may surmise that ocean dynamics, by influencing the large-scale patterns of SST, determines the local correlation between SST and SLP on a basin-wide scale.

The associated vector wind correlation [e.g., Kundu, 1976] with T1 (or equivalently, NINO3) shows largest values over the west-central Pacific (Figure 3a). Meridional convergence toward the equator is consistent with the alignment of the P1 isolines off the equator, and the eastward turning near the equator is consistent with an ageostrophic, across-isobar flow (Figure $3 \mathrm{~b}$ ). This results in a westerly wind anomaly correlation with eastern Pacific warming that is maximum just south of the equator in the west-central Pacific. The southward offset is consistent with a somewhat larger P1 isoline gradient there. These findings, based upon correlations between EOF modes and data fields, are similar to those by Deser and Wallace
[1990], who used a very large scale SST index, and with those of Zebiak [1990], who used a dynamically adjusted wind field. Additional elements of the western Pacific wind field include cyclonic off-equator patterns and easterlies over the far western Pacific. The cyclonic off-equator patterns exist over regions of negative SST correlation (i.e., those regions of off-equator western Pacific cooling relative to eastern Pacific warming). The easterly anomalies in the far western Pacific occur simultaneously with the westerly anomalies in the west-central Pacific. The existence of large-scale equatorial wind anomalies and off-equator wind curl anomalies accentuates the importance of momentum coupling through ocean dynamics (equatorial upwelling and off-equator Ekman pumping) in effecting differences between the principal oceanic and atmospheric patterns of ENSO variability.

Joint variability using SVD was also investigated. Surprisingly, the associated correlation patterns were nearly indistinguishable from the single-field patterns just described. In other words, the variability common to both fields (SST and SLP) that is captured by the SVD analysis is redundant because most of the joint variability is contained in the single-field analysis, at least for the first mode. Newman and Sardeshmukh [1995] provide a theoretical basis for this result where, for the present case, the spatial patterns of SLP are linearly related to the spatial patterns of SST.

3.2.2. Results: Western Pacific region. The maximum variance for SST $\left(0.15\left({ }^{\circ} \mathrm{C}\right)^{2}\right)$ in the western tropical Pacific is about an order of magnitude smaller than that in the east, whereas for SLP the maximum variance $\left(\sim 1 \mathrm{mbar}^{2}\right)$ is comparable to that in the east. A smaller WP region to the west of $160^{\circ} \mathrm{E}$ is considered separately to avoid pattern domination by the large eastern Pacific SST variances. For this WP region the largest SST variances are south of the equator in the Arafura Sea and south and east of New Guinea in the Coral and Solomon Seas, respectively. Maximum variance for SLP occurs off the northern coast of Australia.

Analysis of joint variability using SVD provides the patterns that maximize the variance in common between the fields of SST and SLP. The temporal correlation patterns between the first-mode SVD for SST and the SST and wind data are shown 


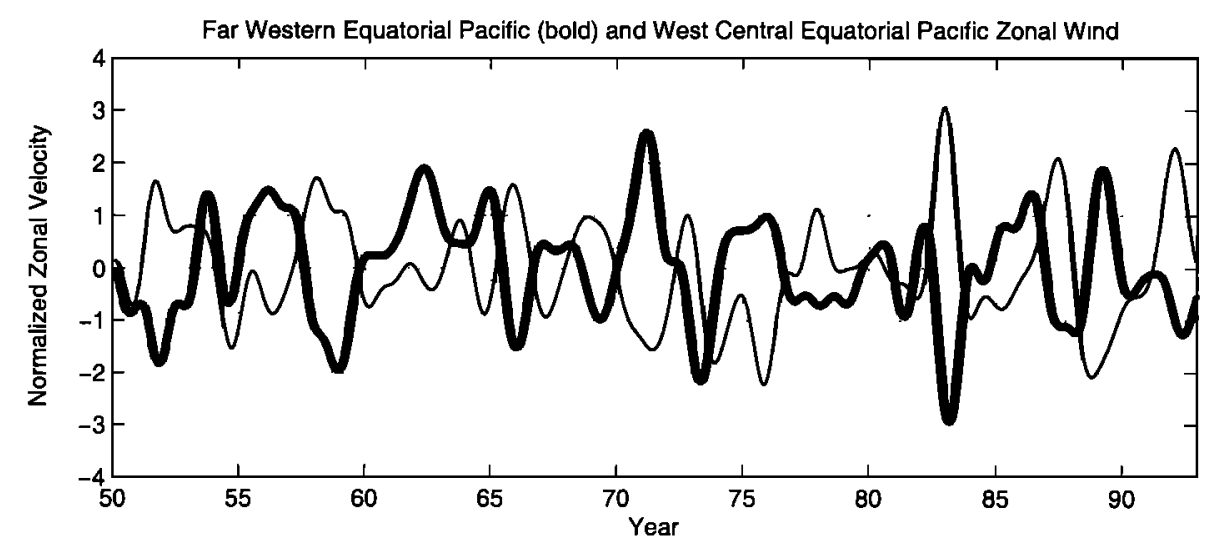

Figure 5. Areal indices for the zonal wind component anomalies on the equator in the far western Pacific near $125^{\circ} \mathrm{E}$ (bold) and in the west-central Pacific near $170^{\circ} \mathrm{W}$. The indices are low-pass-filtered (as given in the text) and normalized to unit standard deviation.

in Figure 4a. Similarly, the patterns of correlation for the second mode are shown in Figure $4 \mathrm{~b}$. As in the autoanalysis, the correlations squared yield the fraction of variance accounted for locally by each mode. The first two modes for the joint variability are separable on the basis of a similar computation for the sampling errors as used for the autoanalysis. The difference is in the calculation of degrees of freedom. In the autoanalysis the independence timescale is estimated with the autocorrelation function using only the left- or the right-hand fields. In the crossanalysis the independence timescale is estimated with the cross-correlation function between the principal components by SVD of the left- (SST) and the right- (SLP) hand fields. The sampling errors of the eigenvalues for the SVD are thus estimated as $\delta s_{x y_{t}}^{2}= \pm s_{x y_{t}}^{2} \sqrt{2 / \eta}$, where the $s_{x y_{t}}$, the elements of the diagonal singular value matrix, are the cross covariances between the $i$ th mode principal components for the left- and right-hand fields. The first two modes in this case represent $80 \%$ and $13 \%$ of the squared cross covariance common to both fields, respectively.

Before describing these SVD modes a digression on variance accounted for is useful since the squared cross covariance common to both fields does not say anything about how much of the left or right field variances can be accounted for by the respective left or right field principal components. Intuitively, for the first mode we know it cannot be more than that associated with the autoanalysis. The fraction of variance $\left(\mathrm{FV}_{t}\right)$ accounted for by the $i$ th (in this case the left-hand field) SVD mode over the whole WP domain is

$$
\mathrm{FV}_{\imath}=\sum_{j=1}^{m_{x}} \rho_{l j}^{2} \sigma_{j}^{2} / \sum_{j=1}^{m_{x}} \sigma_{j}^{2}
$$

where $\rho_{l j}^{2}$ is the correlation squared between the $i$ th mode principal component and the data at each of the $m_{x}$ positions in the domain and $\sigma_{j}^{2}$ is the local variance at each of these positions. Note that for an autoanalysis the numerator of FV, is simply replaced by the $i$ th mode single-field eigenvalue. In the present case the first two modes of the left-hand field (Figures $4 \mathrm{a}$ and $4 \mathrm{~b}$ ) account for $23 \%$ and $33 \%$ of the total variance for SST, respectively, compared with $39 \%$ and $17 \%$ for an autoanalysis (not shown). These differences for SST in the autoanalysis and crossanalysis arise because the autoanalysis describes variability where the largest variances are, while the crossanalysis describes the common variance between the fields where the largest cross covariances are. For the latter the SVD first-mode pattern of correlation (Figure 4a) is largest off the equator near the areal indices WPS and WPN. These results are consistent with Plate 1 where the maximum cross covariance over the western Pacific occurs in the off-equator WPS and WPN regions. The SVD second-mode pattern of correlation (Figure 4b) covers most of the Arafura Sea and the western Pacific equatorial region. Thus the information content for the joint-field SVD is similar but organized differently when compared with the single-field analysis. Completing this digression, we should mention that a canonical correlation analysis was also performed. Similar patterns (not shown) were obtained but with nonseparable modes. The choice, a priori, among different but related analysis techniques is therefore not an obvious one.

The first two SVD modes for SST over the western Pacific may be described as follows. The first mode shows a pattern of symmetric off-equator maxima in SST/SLP correlation. The second mode shows a correlation pattern that is more evenly distributed about the equator with largest values in the southwest half plane centered upon the Arafura Sea. With the sign convention for the wind vector correlation being the same as in Figure 3 the off-equator first-mode pattern shows wind vectors converging on the equator during the warm phase of ENSO when the off-equator SST is anomalously low and conversely during the cold phase of ENSO when the off-equator SST is anomalously high. Over the far western (west-central) equatorial Pacific these equatorially convergent winds turn anticylonically (cyclonically) to become easterly (westerly) wind anomalies. The second-mode pattern also shows easterly winds over the western Pacific during the warm phase of ENSO that fill the entire WP domain. How these two modes evolve relative to the eastern Pacific (NINO3 region) SST and their relation to the actual wind anomalies is developed next.

3.2.3. Relationships between regions. The foregoing statistical patterns that consist of negative SST/SLP correlations over both the eastern equatorial and the western off-equatorial Pacific regions that are out-of-phase with each other are regular features of ENSO (Figure 2). The associated oppositely directed zonal wind anomalies over the west-central and far western equatorial Pacific, as shown in Figure 5, are also regular features of ENSO. For almost every ENSO cycle within 
this data set (spanning 1950-1992), SST and SLP are observed to vary inversely over the equatorial eastern Pacific without phase lag (Figure 2). Coincident with this is an inverse relationship between SST and SLP near $12^{\circ} \mathrm{S}$ and $12^{\circ} \mathrm{N}$ in the western Pacific (Figure 2) where SLP lags SST by $\sim 1$ month. Essentially concomitant with each mature El Niño, westerly wind anomalies in the west-central equatorial Pacific are opposed by easterly wind anomalies in the far western equatorial Pacific.

Taking the Pacific single-field first-mode SST pattern (Figure 3 ) as a reference (recall that its time evolution function is equivalent to the NINO3 index), we find that the western Pacific joint-field first and second SVD modes for SST (Figures $4 \mathrm{a}$ and $4 \mathrm{~b}$, respectively) both lag the NINO3 index by $\sim 1$ month (SL > 99\%) and 8 months (SL > 95\%), respectively. Since the SVD first mode has easterly winds over the far western Pacific and the SVD second mode has easterly winds over the entire equatorial western Pacific the sequence is such that during the mature phase of El Niño, easterlies first form over the far western Pacific and then fill in over the entire western Pacific. Again, with the NINO3 index as reference and correlating this with the SST and vector wind anomalies over the entire WP domain beginning with a lead of 10 months prior to peak NINO3 warming and ending with a lag of 10 months after peak NINO3 warming the patterns develop as follows (Plate 2). As the NINO3 region warms, the western Pacific off-equator regions cool with peak NINO3 warming and offequator western Pacific cooling occurring within a month or two of each other. Once these off-equator patterns develop, easterlies form over the far western Pacific and, as they develop, the off-equator patterns start to wane and SST begins to increase in the far western Pacific. This region of increasing SST expands eastward along with the easterlies as the NINO3 warming abates.

Inspection of the anomaly data fields shows that although each ENSO cycle evolves somewhat differently, the evolution is generally consistent with the above statistical description. The 1982/1983 El Niño provides an example (Plate 3). Here the (low-pass-filtered) western Pacific anomaly fields for the sequence July 1982 to April 1983 brackets the period of peak El Niño warming. The waxing and waning of the off-equator patterns with El Niño warming (the westernmost tip of which is seen near the dateline) is clearly evident. In particular, note the ridge of high SLP that forms between $10^{\circ} \mathrm{N}$ and $20^{\circ} \mathrm{N}$ in the January 1983 and April 1983 fields and its associated easterly wind anomalies over the western half of the domain. Similar patterns of opposite sign (not shown) occur during the La Niña cold phase of ENSO.

\subsection{Western Pacific Variability: Thermodynamics}

Unlike the eastern Pacific NINO3 region where SST and SLP covary synchronously, the western Pacific off-equator regions show SLP lagging SST by $\sim 1$ month, suggestive of a causal relationship. We therefore examine whether or not estimates of anomalous latent heat release can account for the observed time derivative of SLP amounting to $\sim 0.5-1 \mathrm{mbar}$ month $^{-1}$. The working hypothesis is that small increases (decreases) in SST tend to lower (raise) SLP by enhancing (degrading) conditions of the atmospheric background state that favor convective activity. Contributing to this background state is the nonlinear relationship between specific humidity $(q$, and temperature (Clausius-Clapeyron equation). The change in $q$, with respect to temperature is $\sim 1.5$ times greater near $30^{\circ} \mathrm{C}$ than it is near $20^{\circ} \mathrm{C}$. The latter is close to conditions in the eastern Pacific, where the lower troposphere near the equator is reasonably stable for much of the year, and the background state is one of subsidence rather than convection. Latent heat release, as a factor in maintaining the pressure field in the western Pacific, is provided by deep convective activity. Mapes and Houze [1993] documented this activity over the warm pool during November-February. Here the lower troposphere is almost always in a state of incipient instability, especially in late fall and winter when the South Pacific Convergence Zone is nearing its southernmost position and SST is nearing its maximum $\left(>29^{\circ} \mathrm{C}\right)$ [e.g., Philander, 1990].

The impact that small temperature changes may have on SLP can be assessed by considering a hydrostatic atmosphere. Admittedly, this is a simplification that neglects buoyancy changes in the affected air parcels and surface divergence since heating would not be realized as a local temperature change unless accompanied by local subsidence. For an order of magnitude estimate, however, we feel that this is a reasonable approach because SLP gradients are hydrostatically generated from the vertical mixing of large-scale SST gradient effects across the atmospheric boundary layer [Lindzen and Nigam, 1987; Wallace et al., 1989].

A preliminary analysis of the TOGA COARE data by Parsons et al. [1994] provides a case study of intense convection over an $\sim 500 \mathrm{~m}$ column of air for $\sim 1$ day. Latent heating was $\sim 100 \mathrm{~W} \mathrm{~m}^{-2}$, about an order of magnitude larger than sensible heating. Using cloud statistics from Mapes and Houze [1993], an estimate can be made of the percentage of deep cloud convection as represented by the $208^{\circ} \mathrm{K}$ cloudiness spectrum. Referring to the region east of New Guinea in Figure 4a (the area of order $10^{6} \mathrm{~km}^{2}$ enclosed by the $\rho=0.8$ contour), the cloudiness spectrum suggests that $\sim 10 \%$ of this area would be subject to deep convection at any given time. The case study combined with the cloud statistics suggest that $\sim 10 \mathrm{~W} \mathrm{~m}^{-2}$ manifests itself as a release of latent heat in the lower troposphere during the peak of the annual cycle during the November-February period. If it is assumed that the interannual anomaly for this heating is an order of magnitude smaller, or 1 $\mathrm{W} \mathrm{m}^{-2}$, is this adequate to account for the SST/SLP relationship?

Denoting SLP by $P_{b}$, the pressure $P_{z}$ at a height $\Delta z$ above the sea surface is given by the hypsometric equation $P_{z}=$ $P_{h} e^{-\alpha}$, where $\alpha=\Delta z / \bar{H}$ and $\bar{H}=R_{d} \bar{T}_{z} / g$ is the scale height related to the bulk virtual temperature $\bar{T}_{\nu}$, and the dry air gas constant $R_{d}$. Increasing temperature causes pressure to drop. $P_{z}$ is a function of $\bar{T}_{y}$, so the heating required to raise the temperature of an air column by an amount $\Delta \bar{T}_{v}$, can be approximated by $\Delta Q=c_{p} \Delta \bar{T}_{v} M$, where $c_{p}$, is the specific heat of dry air and $M$ is the air column mass.

For an order of magnitude argument, let $\Delta z=1000 \mathrm{~m}$, $P_{b}=1010 \mathrm{mbar}, R_{d l}=287 \mathrm{~J} \mathrm{Kg}^{-1}{ }^{\circ} \mathrm{K}^{-1}, g=9.8 \mathrm{~m} \mathrm{~s}^{-2}$, and $\bar{T}_{z}=300^{\circ} \mathrm{K}\left(27^{\circ} \mathrm{C}\right)$, assuming a surface temperature of $30^{\circ} \mathrm{C}$, a lapse rate of $\sim 6^{\circ} \mathrm{C} / 1000 \mathrm{~m}$, and $c_{p}=1004 \mathrm{~J} \mathrm{~K} \mathrm{~g}^{-1}{ }^{\circ} \mathrm{K}^{-1}$. Recalling an excitation rate of $|\delta P / \Delta t|=0.5-1$ mbar month ${ }^{-1}$, a 1 mbar decrease using the hypsometric equation requires an air column of $1000 \mathrm{~m}$ to increase temperature by $\sim \Delta \bar{T}_{z}=3^{\circ} \mathrm{K}$. If the height of the air column is increased (more mass), a smaller temperature change would be required. Evaluating the heat equation $\left(\Delta Q /(A \Delta t)=c_{p} \Delta \bar{T}_{v} M /(A \Delta t)\right)$ requires an estimate of the mass per unit area $(M / A)$ which follows from the hydrostatic relationship. For the initial state with $\bar{T}_{v}=300^{\circ} \mathrm{K}, \Delta P \approx 109 \mathrm{mbar}$, and converting mbar to 

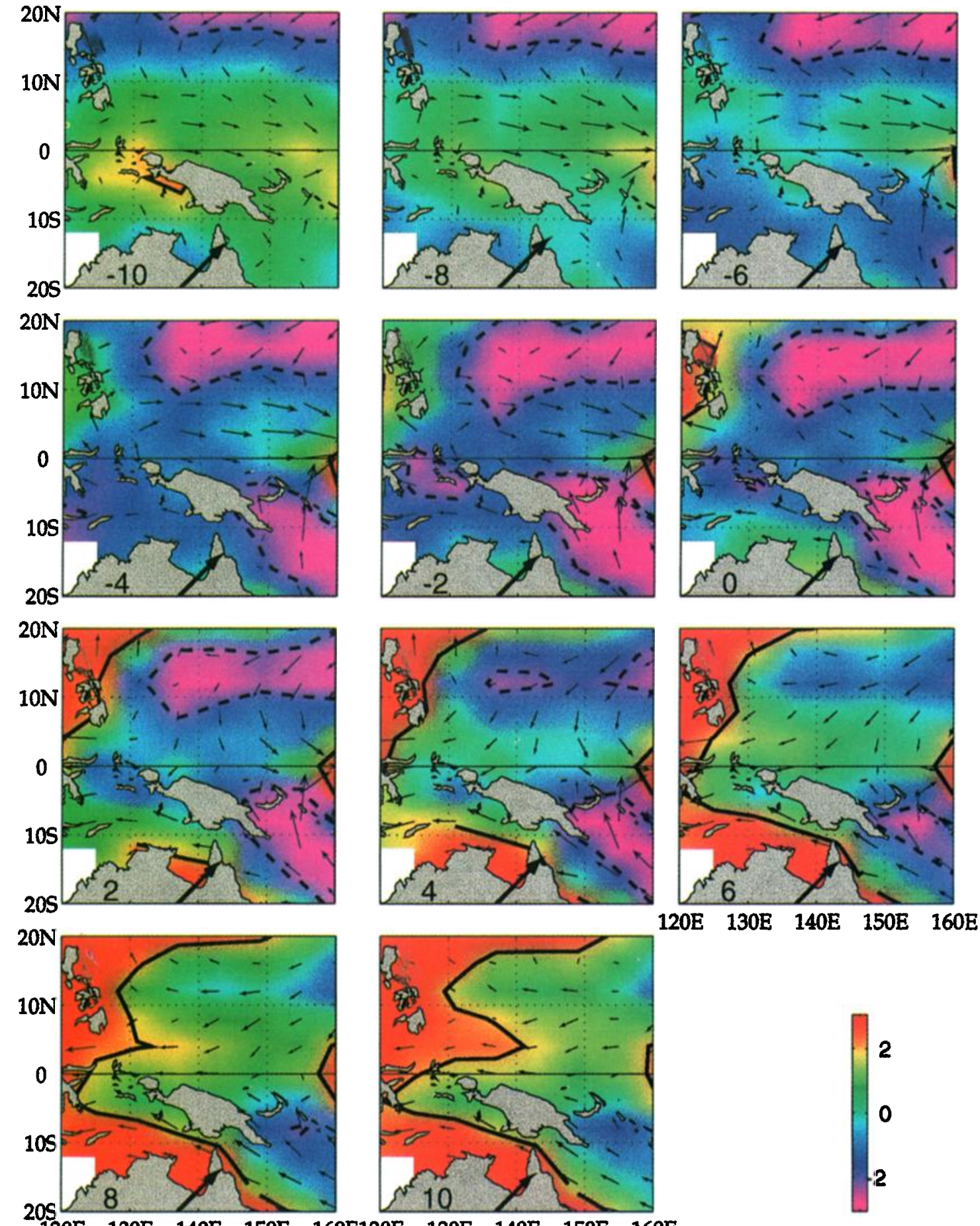

120E $130 \mathrm{E} \quad 140 \mathrm{E} \quad 150 \mathrm{E} \quad 160 \mathrm{E}$

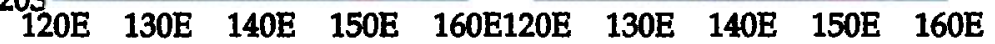

Plate 2. A sequence of lagged correlation maps between T1 (equivalent to the NINO3 index) and the anomalies of SST and surface wind over the western Pacific (WP) domain from 10 months prior to 10 months after peak ENSO warming.

$\mathrm{N} \mathrm{m}{ }^{-2}$ gives $M / A=\left(\Delta P \times 10^{2}\right) / g \approx 1100 \mathrm{Kg} \mathrm{m}^{-2}$. With $\Delta t \approx 3 \times 10^{6} \mathrm{~s}(\sim 1$ month) it follows that $\Delta Q /(A \Delta t) \approx 1$ $\mathrm{W} \mathrm{m}{ }^{-2}$. Thus a subtlely small anomalous heating (an order of magnitude smaller than available during the peak of the annual cycle) can account for the observed rate of SLP change. The point is that only a very small perturbation in heating (less than the errors involved in either measurements or models) appears to be sufficient to effect the interannual variations of the annual cycle as manifest in ENSO.

\section{Discussion and Summary}

The observational basis for ENSO-related ocean-atmosphere coupling of momentum and heat was examined using 43 years (1950-1992) of SLP and surface wind data from COADS and SST data derived therefrom [Smith et al., 1996]. Distinguishing among the various mechanisms advanced to explain ENSO requires an improved understanding of where such coupling occurs and hence the motivation for our analyses in 

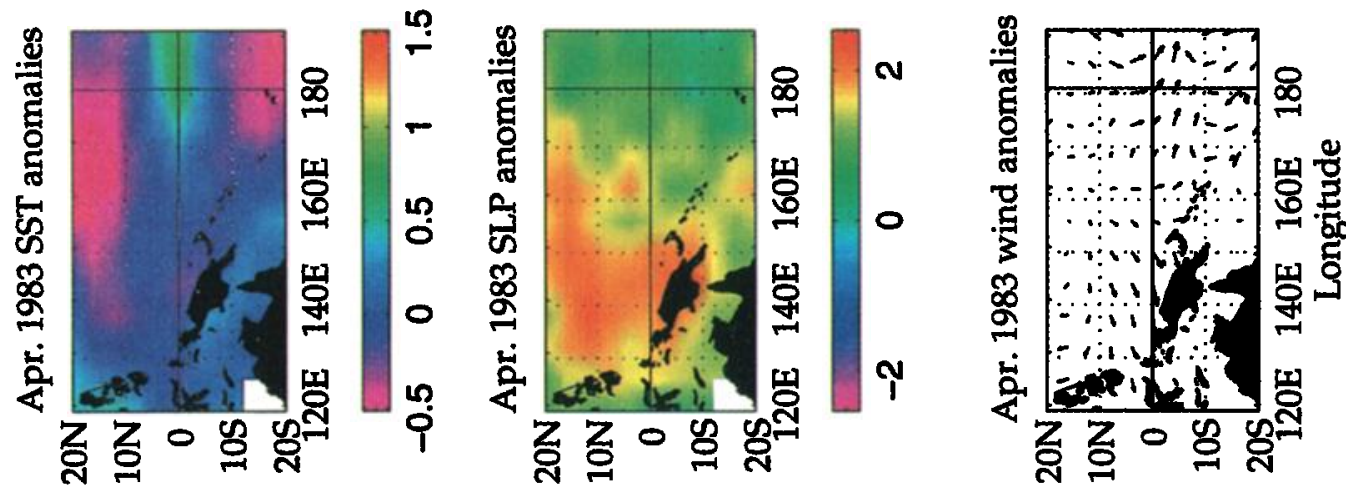

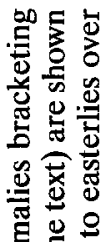

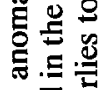
焉总焉
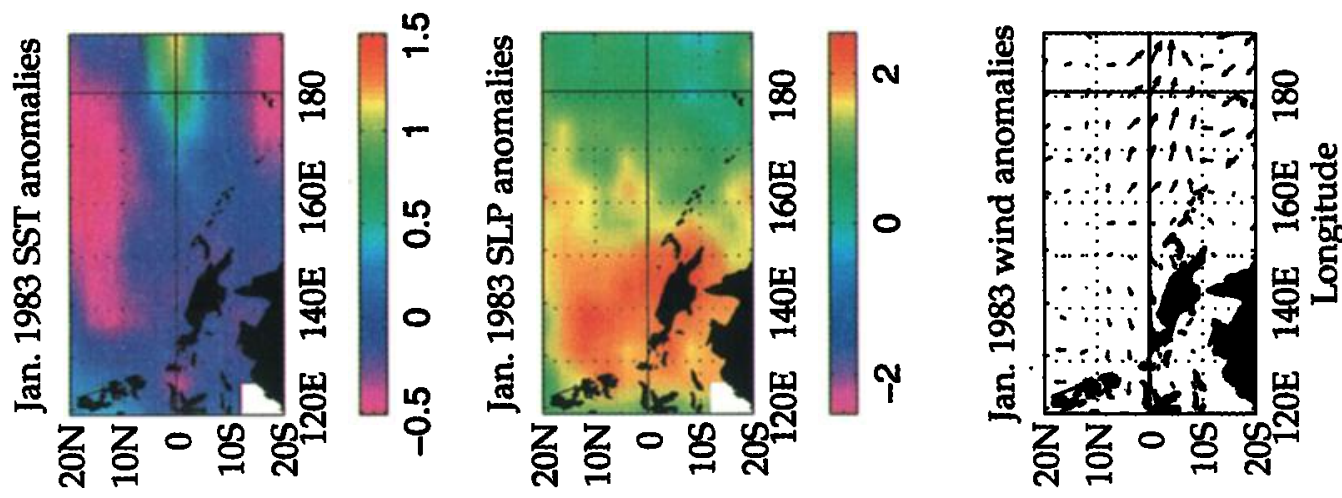

융 政

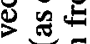

(2)

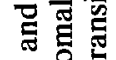
氙志导

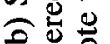

는 卷客焉 తิ 本是完

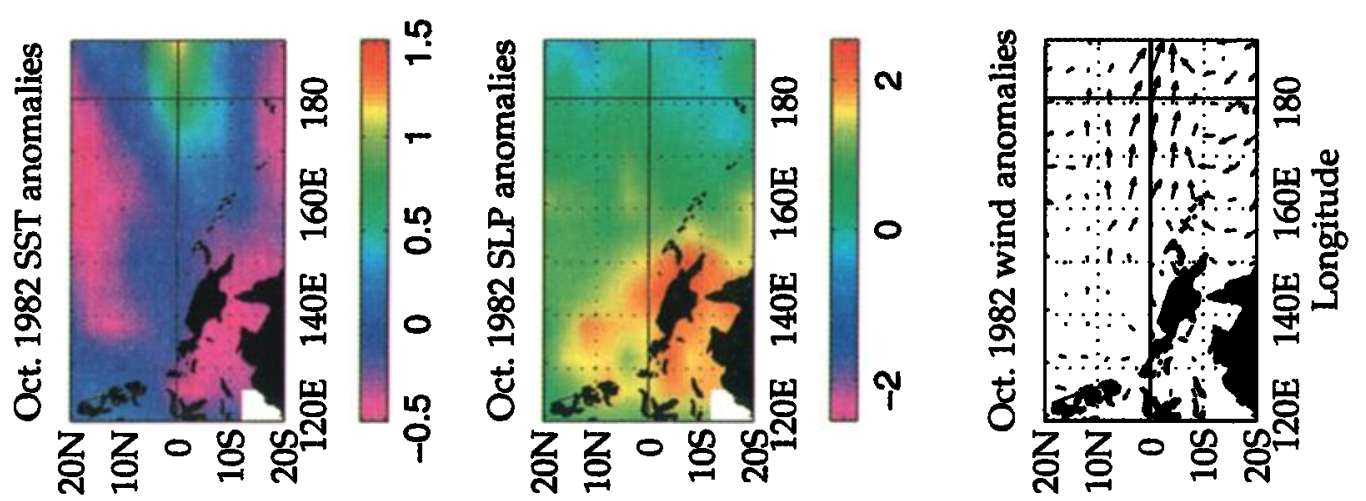

을 몬 氖 可 E

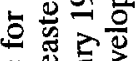
过

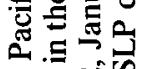
둴. 包岇 웜용

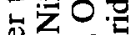
ปั⿴囗十丁

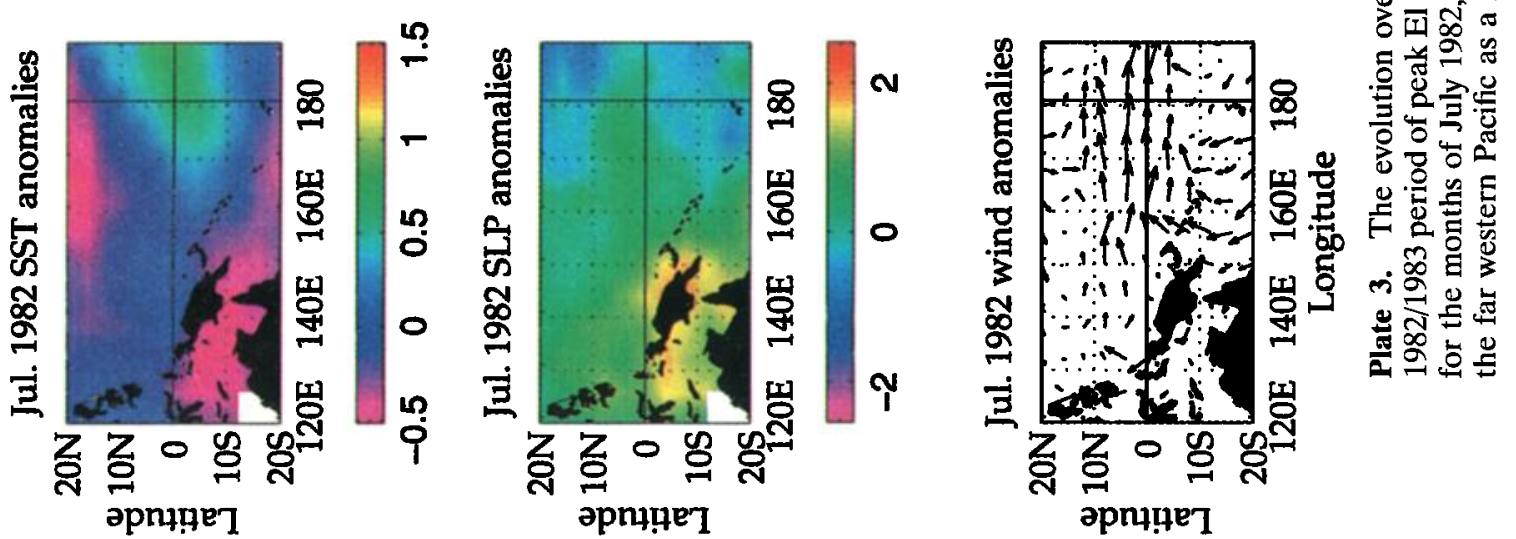


section 3. Our emphasis was on the western tropical Pacific where the evolution of off-equator patterns of correlated SST and SLP anomalies were found to be related to zonal wind anomalies over the equatorial western Pacific. These western Pacific wind anomalies evolve in opposition to central Pacific wind anomalies during the ENSO cycle.

Analyses began with the calculation of the local correlation between SST and SLP over the global tropics. The pattern suggests distinctly different behaviors between the eastern and western hemispheres. East of the dateline, interannual anomalies of SST and SLP are generally negatively correlated (positive SST anomalies related to negative SLP anomalies and conversely), while west of the dateline, the correlation is mostly positive. A negative correlation is consistent with a local response of a hydrostatic atmosphere to the surface boundary condition, but this is not the case for a positive correlation. For example, relatively high SST underlies relatively high SLP (a positive correlation) over the subtropical gyres of the world's oceans, but this is understood in terms of the large-scale ocean response, via Sverdrup dynamics, to a pressure pattern determined globally, not locally (e.g., the teleconnection pattern of Horel and Wallace [1981]). In the tropics the region of largest positive correlation is the eastern Indian Ocean. As illustrated in Figure 2, the maximum positive correlation region centered on $0^{\circ}, 83^{\circ} \mathrm{E}$, SST actually lags SLP during the ENSO cycles of the $1980 \mathrm{~s}$, arguing against Indian Ocean air-sea coupling as causal. This finding together with the observation of maximum variances over the Pacific Ocean led to our subsequent Pacific Ocean focus.

The eastern and western regions of the tropical Pacific also behave differently, with the dateline, where the correlation between SST and SLP is lowest, being the approximate delimiting point. East of the dateline, there is a broad region of negatively correlated SST and SLP centered on and symmetric about the equator. West of the dateline, there are also regions of negative correlation symmetric about the equator but located $10^{\circ}-20^{\circ}$ poleward from the equator. In contrast to these regions of negative correlation the equatorial region in the west is one of small positive correlation. These Pacific patterns are reminiscent of a Gill [1980] atmosphere response to localized heating in the vicinity of the dateline. East and west of such heating are forced Kelvin and Rossby wave responses, respectively. The relatively broad (with respect to an oceanic Rossby radius of deformation) meridional scale observed in these correlation patterns is consistent with arguments on meridional scale broadening by air-sea coupling by Wang and Weisberg [1994, 1996]. These basic patterns and their relationship to the surface winds are what we set out to describe using single-field EOFs and joint-field SVDs.

For the basin-scale tropical Pacific features, single-field EOFs provided sufficient descriptors; neither joint-field SVDs nor canonical correlations offered improvements. The correlation pattern between the SST first-mode EOF and the SST data shows a broad region of positive correlation, generally centered on and symmetric about the equator with an eastward increasing meridional scale. This contrasts with negative, symmetric but off-equator patterns to the west. The correlation between this first mode and the surface wind vector anomalies shows maximum values in a region centered just south of the equator between the dateline and $\sim 160^{\circ} \mathrm{W}$. This vector correlation pattern, with maximum westerly wind anomalies positioned a few degrees south of the equator near $170^{\circ} \mathrm{W}$ and with winds converging meridionally from off the equator, was previously identified by Deser and Wallace [1990]. Deser and Wallace used the correlations between a large-scale SST index (the dateline to South America and $6^{\circ} \mathrm{N}-6^{\circ} \mathrm{S}$ ) and SST, SLP, surface winds, and outgoing long wave radiation (OLR) for warm event composites over the months of July-November (equatorial cold tongue season) and December-February (mature phase of El Niño). They emphasized the meridional convergence and demonstrated its relationship to negative OLR anomalies and hence increased convection by convergent moisture flux. From this our consistent field correlations and in situ measurements during the 1988-1992 La Niña to El Niño transition [Weisberg and Wang, 1997b] it may be surmised that the west-central equatorial Pacific is the site of maximum zonal wind and latent heat anomalies and hence the site of maximum ocean-atmosphere coupling for both momentum and heat flux on interannual timescales. Going from the July-November to the December-February composites, Deser and Wallace [1990] showed the development of off-equator positive SLP anomalies and easterlies over the western part of the basin. This is consistent (implicitly) with the off-equator region of negative correlation between SST and SLP shown in Plate 1 and Figure 2.

The patterns described are also consistent with those of Zebiak [1990]. On the basis of the tropical Pacific Florida State University (FSU) wind analysis, surface pressure and dynamically adjusted wind fields were derived and used to infer atmospheric heating via a model similar to Gill [1980]. Like Deser and Wallace [1990], a convergence of the surface winds in the west-central Pacific (near $170^{\circ} \mathrm{W}$ ) just south of the equator during the mature phase of $\mathrm{El} \mathrm{Niño} \mathrm{is} \mathrm{associated} \mathrm{with} \mathrm{large}$ inferred heating there in agreement with anomaly fields of OLR and highly reflective clouds. An accompanying SST anomaly field shows off-equator negative SST anomalies in the western Pacific consistent with Plate 1 and Figure 2. Moreover, west of the dateline are easterly wind anomalies.

Although the single-field analyses provide a large-scale picture over the entire tropical Pacific domain, the details of the western Pacific, by virtue of different symmetry properties, are obscured. Analyses of a smaller western Pacific domain were performed to clarify these. We employed single-field EOF, joint-field SVD, and canonical correlation analyses focusing upon the joint field SVDs as providing the most straightforward, separable modes. We point this out because there appears to be no simple a priori rule regarding which analysis is best. The two leading modes are important. The first (Figure 4a) shows that for a negative off-equator SST anomaly, there exists an equatorially convergent easterly wind anomaly over the far western Pacific. The other (Figure 4b) shows that for a positive, more equatorial SST anomaly centered about the Arafura Sea west of New Guinea, there exists an easterly wind anomaly over this entire western Pacific domain. Both of these patterns are related to the structure of the correlation between SST and SLP shown in Plate 1. Each contributes to the evolution of easterly wind anomalies over the western tropical Pacific during the mature phase of El Niño as shown in Plate 2.

From these results the Deser and Wallace [1990] and Zebiak [1990] analyses, and the in situ data analyses of Weisberg and Wang [1997b] we may deduce an origin for the SST and SLP relationship in the western Pacific and how this may relate to the evolution of ENSO. The basic idea is given by Weisberg and Wang [1997a]. In accordance with a Gill [1980] atmosphere heated about the equator in the west-central Pacific, equatorial 
westerly winds will result, driven in part by a pair of off-equator cyclones. A local effect of cyclonic wind stress curl is Ekman pumping that raises the thermocline along the NECC trough [e.g., White et al., 1987, 1989; Kessler, 1990] tending to cause off-equator negative SST anomalies relative to the positive SST anomalies centered about the equator to the east. Thus, as convection moves eastward into the west-central Pacific from the west, these off-equator cold SST anomalies can form in the wake of the eastward moving cyclonic wind stress curl, both by local Ekman pumping and the continual elevation of the thermocline by westward propagating, off-equator forced Rossby waves. Off-equator cold SST anomalies in turn can produce off-equator high SLP anomalies. Off-equator high SLP anomalies can drive equator-convergent winds that turn anticyclonically to easterlies over the far western Pacific [Gill, 1980], as seen in the SVD mode 1 [Figure 4a]. The subsequent impact upon a mature El Niño may then proceed as follows. Easterly winds cause upwelling that propagates eastward along the equator as a forced Kelvin wave, modifying the thermocline and SST anomalies along the way, while deepening the thermocline and increasing SST over the far western Pacific. The reversal of the zonal wind anomalies over the far western Pacific (from westerlies to easterlies) also reverses the offequator wind stress curl anomalies, leading to a decrease (and eventual reversal in sign) in the off-equator patterns. Western Pacific easterlies are enhanced as SST increases over the entire far western Pacific, as seen in the SVD mode 2 (Figure 4b). This is similar to the mechanism of the delayed oscillator except that instead of relying upon upwelling oceanic Rossby waves generated over the eastern equatorial Pacific that propagate to and reflect from the western boundary as an upwelling Kelvin wave, we are deducing a forced ocean-atmosphere Rossby and Kelvin wave response owing to atmospheric heating over the western Pacific. What is envisaged may be thought of as a hybrid between the delayed oscillator and the slowmode paradigms, in which ocean-atmosphere coupling is important in the western Pacific, and the region of the most active coupling for both momentum and heat flux is the equatorial west-central Pacific where the correlation between SST and SLP is a minimum.

This raises an interesting dilemma. While the correlation pattern between SST and SLP is obviously related to ENSO, it may not be indicative of where the most active oceanatmosphere coupling occurs either for momentum flux, latent heat flux, or the release of latent heat to the atmosphere through convection. Such interpretations are complicated by different mechanisms controlling the SST and SLP anomalies regionally. For instance, SST anomalies are minimum in the west, where the thermocline is relatively deep and the lower troposphere is almost always in a state of incipient instability (therefore also potentially deep), so that ocean-atmosphere dynamics and thermodynamics are governing; whereas they are maximum in the east, where the thermocline is shallow and the lower troposphere is relatively stable (therefore also shallow), so that ocean dynamics are primarily governing. In contrast, SLP shows comparable variability in both the east and the west. Second, a negative correlation between SST and SLP (indicative of a local hydrostatic relationship) is identified in several regions, but only in the off-equator western Pacific does SST lead SLP, suggesting causality. For the southern region, Gent [1991] shows that the ocean heats the atmosphere on an annual average, supporting the notion that SST may be causal.
It is interesting to question then how much of the high SST/ SLP correlation in the east is due to a local causal relationship versus how much is a consequence of ocean and atmosphere responses to coupling occurring elsewhere. Viewing the regression coefficient $\left(\mathrm{mbar}^{\circ} \mathrm{C}^{-1}\right)$ as a primitive coupling coefficient linking SLP to SST, the off-equator western values are about twice that of the eastern value. Such regression in the west, however, accounts for a smaller percentage of the SLP variance. At the very least then, linear correlations may not properly reflect the nature of coupling. Third, correlations may be degraded by processes occurring with different spatial scales. An example was given with regard to Plate 1 . Here the westernmost extension of ocean-dynamics-induced ENSO warming overlapped the pivot point of the Southern Oscillation thereby causing a positive correlation on the equator in the western Pacific versus a negative correlation in the eastern Pacific. Small shifts in position of these features from one ENSO cycle to another result in a region of minimum correlation in the west-central Pacific, masking the region for which we know that both momentum and heat flux couplings are large. Finally (and in an as yet unsolved manner), it is the SST, as opposed to the anomalous SST, that determines the predisposition for convection and hence the release of latent heat. Does this account for the disparity between the relative SST and SLP variabilities in the east and west?

The potential impact of small SST variability on western Pacific SLP was assessed by considering a hydrostatic atmosphere influenced by latent heat release due to convective activity. Using the Parsons et al. [1994] TOGA COARE data analyses with the Mapes and Houze [1993] cloudiness spectrum as an areal measure of deep convection, only $\sim 10 \%$ of the available heating (or $1 \mathrm{~W} \mathrm{~m}^{-2}$ ) is required to account for the SLP anomaly rate of change ( 1 mbar month $\left.{ }^{-1}\right)$. The subtlety of this condensation heating requirement in the western Pacific underscores the complexity of ocean-atmosphere coupling for ENSO and the idea that important regions may not always be associated with maximum variability. Here the disproportionate influence (implied by the data) that minimum SST variability has on SLP over the western Pacific may reflect the different background states characterized by incipient instability in the west, where the atmospheric boundary layer may be 2-3 km deep, versus relative stability in the east, where the boundary layer is much shallower. This subtlety and complexity in the nature of ocean-atmosphere coupling is further compounded by the controls placed upon latent heat flux by wind speed, ocean-atmosphere temperature differences, and relative humidity and on the release of latent heat by the largescale atmospheric circulation [e.g., Liu et al., 1994]. Such factors have not been considered in our analyses.

In summary, a reexamination of interannual anomaly fields of SST, SLP, and surface winds over the global tropics suggests that the equatorial west-central Pacific near $170^{\circ} \mathrm{W}$ and the western Pacific off-equator regions are important regions of ocean-atmosphere coupling for ENSO. Deducing oceanatmosphere coupling from correlations between SST and SLP is not at all obvious. Our analyses suggest that western Pacific ocean-atmosphere coupling provides a mechanism of negative feedback that tends to reverse the evolution of anomalies during the mature phases of ENSO. This mechanism is complementary to others, all of which are distinguished by the different regions where active ocean-atmosphere coupling occurs. 


\section{Appendix: Principal Components for Single-Field and Joint-Field (SVD) Analyses}

Let the fields of SST and SLP be represented by the matrices $\mathbf{X}$ and $\mathbf{Y}$ of dimension $m_{x} \times N$ and $m_{y} \times N$, respectively, where $m_{x}$ and $m_{y}$ are the spatial dimensions for these fields and $N$ (=516 months) is their common time dimension. We define $\mathbf{X}$ as the left-field variable and $\mathbf{Y}$ as the right-field variable. The combined temporal covariance matrix is

$$
\mathbf{C}=\left(\begin{array}{ll}
\mathbf{C}_{x x} & \mathbf{C}_{x y} \\
\mathbf{C}_{y x} & \mathbf{C}_{y y}
\end{array}\right)
$$

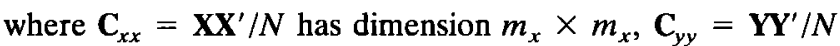
has dimension $m_{y} \times m_{y}$, and $\mathbf{C}_{x y}=\mathbf{X Y} / N$ has dimension $m_{x} \times m_{y}$. Generally, $m_{x} \neq m_{y}$, but for our analyses, $m_{x}=$ $m_{y}$. If each time series is standardized (normalized by its standard deviation), then covariances become correlations. Results using this approach were found to be similar to those using covariances, so our discussions are limited to the latter. The diagonal elements of $\mathbf{C}$ relate to the autoanalysis or single-field analyses of the left and right fields and either $\mathbf{C}_{x y}$ or $\mathbf{C}_{y x}$ relates to the crossanalysis or joint analysis.

For the autoanalysis the results consist of eigenvectors, spatial patterns, and their associated principal components (PCs) or time series. Using the left field, for example, a SVD of the data matrix directly provides the spatial eigenvectors and temporal coefficients in one step, i.e., $\mathbf{U}_{x} \mathbf{S}_{x} \mathbf{V}_{x}^{\prime}=\mathbf{X}$, where $\mathbf{V}_{x}^{\prime}$ denotes the transpose of $\mathbf{V}_{x}$. The square orthogonal matrix $\mathbf{U}_{x}$ consists of $m_{x}$ orthonormal column vectors and is the set of spatial patterns where the first column is the first-mode pattern. Each element is a spatial weight at its corresponding position in the data field. The diagonal matrix $\mathbf{S}_{x}$ is the set of singular values that contains the units and thus the scaling of the data field. The orthogonal matrix $\mathbf{V}_{x}$ of dimension $N \times m_{x}$ consists of $m_{x}$ orthonormal PCs where the first column is the first-mode time series. The invariant is the sum of all squared elements of $\mathbf{X}$ It is also equal to the sum of each squared element $\left(s_{x_{t}}^{2}\right)$ of $\mathbf{S}_{x}$ or trace $\left(\mathbf{S}_{x}^{2}\right)=N$ [trace $\left.\left(\mathbf{C}_{x x}\right)\right]=N$ [trace $\left(\Lambda_{x}\right)$ ]. The diagonal matrix $\Lambda_{x}$ with eigenvalue elements $\lambda_{x_{x}}$ is the eigenvalue matrix obtained by computing EOFs (a special case of SVD) of $\mathbf{C}_{x x}$, i.e., $\mathbf{U}_{x} \boldsymbol{\Lambda}_{x} \mathbf{U}_{x}^{\prime}=\mathbf{C}_{x x}$. The trace $\left(\boldsymbol{\Lambda}_{x}\right)$ is the total temporal variance of $\mathbf{X}$, so the singular value matrix is related to the eigenvalue matrix by $\mathbf{S}_{x}=\sqrt{N \Lambda_{x}}$. Each element of $\Lambda_{x}$ is $\lambda_{x l}$ and is the temporal variance accounted for by the $i$ th mode and is organized as a hierarchy from first mode (maximum) to last mode (minimum). The first mode consists of the first column of $\mathbf{U}_{x}$ (spatial pattern) and the first row of $\mathbf{S}_{x} \mathbf{V}_{x}^{\prime}$ (dimensional time series), so $\mathbf{U}_{x}^{\prime} \mathbf{X}=\mathbf{X}=\mathbf{S}_{x} \mathbf{V}_{x}^{\prime}$. Note that $\boldsymbol{\Lambda}_{x}=\mathbf{X X}^{\prime} / N$. The invariant quantity, trace $\left(\mathbf{S}_{x}^{2}\right)$, is therefore the same whether spatial or temporal covariances are computed for $\mathbf{C}_{x x}$, but the eigenvalues are not. For spatial covariances, $\mathbf{S}_{x}=\sqrt{m_{x} \Lambda_{x}}$, and the first mode consists of the first column of $\mathbf{U}_{\boldsymbol{x}}$ (time coefficients) and the first row of $\mathbf{S}_{\boldsymbol{x}} \mathbf{V}_{\boldsymbol{x}}^{\prime}$ (spatial pattern). All of the above relationships are equally applicable to the $\mathbf{Y}$ (right) field.

For the cross analysis the joint variability between $\mathbf{X}$ and $\mathbf{Y}$ can be characterized by an SVD of $\mathbf{C}_{x y}$, i.e., $\mathbf{U}_{x y} \mathbf{S}_{x y} \mathbf{V}_{x y}^{\prime}=\mathbf{C}_{x y}$. The square orthogonal matrices $\mathbf{U}_{x y}$ and $\mathbf{V}_{x y}$ are the left $\left(m_{x} \times m_{x}\right)$ and right $\left(m_{y} \times m_{y}\right)$ set of orthonormal column vectors that are the left- and right-singular vectors or spatial patterns, respectively. For each of these the first column is the first-mode singular vector or spatial pattern. The PCs are obtained from $\mathbf{U}_{x y}^{\prime} \mathbf{X}=\mathbf{X}_{x y}$ for the left field and $\mathbf{V}_{x y}^{\prime} \mathbf{Y}=\mathbf{Y}_{x y}$ for the right field, and the first row of each represents the firstmode time coefficients. The diagonal matrix $\mathbf{S}_{x y}$ is the singularvalue matrix where each element $\left(s_{x y}\right)$ along the diagonal is the singular value associated with the $i$ th mode and is the cross covariance of the left and right $i$ th-mode PCs, i.e., $\mathbf{S}_{x y}=$ $\mathbf{X}_{x y} \mathbf{Y}_{x y}^{\prime} / N$. The invariant quantity is the sum of each squared element $\left(s_{x y}^{2}\right)$ of $\mathbf{S}_{x y}^{2}$ or trace $\left(\mathbf{S}_{x y}^{2}\right)$ and is the total squared cross covariance between the fields. It is also equal to trace $\left(\mathbf{C}_{x y} \mathbf{C}_{x y}^{\prime}\right)=\operatorname{trace}\left(\mathbf{C}_{x y}^{\prime} \mathbf{C}_{x y}\right)$, where $\mathbf{C}_{x y}^{\prime} \mathbf{C}_{x y}=\mathbf{U}_{x y} \mathbf{S}_{x y}^{2} \mathbf{U}_{x y}^{\prime}$ and $\mathbf{C}_{x y} \mathbf{C}_{x y}^{\prime}=\mathbf{V}_{x y} \mathbf{S}_{x y}^{2} \mathbf{V}_{x y}^{\prime}$. Each squared element $\left(s_{x y_{1}}^{2}\right)$ is the maximum possible squared cross covariance common to both fields for the $i$ th mode and is organized as a hierarchy from first mode (maximum) to last mode (minimum).

Canonical correlation analysis entails a similar sequence of calculations except that $\mathbf{C}_{x y}=\mathbf{X Y}^{\prime} / N$. Thus the cross covariance between the two fields is computed with the left and right single-field PCs, and each squared element $\left(s_{x y}^{2}\right)$ is the maximum possible correlation squared between these two fields.

Acknowledgments. We thank S. Woodruff and S. Worley for providing the COADS data, M. Minton and J. Harris for their assistance with the COADS data files, F. Marks for discussions regarding western Pacific variability, C. Landsea for review of the manuscript, and C. Thacker for guidance on principal component analysis. R. Weisberg acknowledges support from the NOAA, Office of Global Programs, grant NA56GP0241. Discussions with C. Wang, T. Y. Tang, and J. Virmani were instrumental in formulating the conceptual model discussed herein.

\section{References}

Battisti, D. S., and A. C. Hirst, Interannual variability in the tropical atmosphere-ocean model: Influence of the basic state, ocean geometry and nonlinearity, J. Atmos. Sci., 45, 1687-1712, 1989.

Bretherton, C. S., C. Smith, and J. M. Wallace, An intercomparison of methods for finding coupled patterns in climate data, J. Clim., 5, 541-560, 1992.

Deser, C., and J. M. Wallace, Large-scale atmospheric circulation features of warm and cold episodes in the tropical Pacific, J. Clim., 3, 1254-1281, 1990.

Diaz, H. F., and V. Markgraf, El Niño: Historical and Paleoclimatic Aspects of the Southem Oscillation, 476 pp., Cambridge Univ., Press, New York, 1992.

Enfield, D. B., and D. A. Mayer, Tropical Atlantic SST variability and its relation to El Niño-Southern Oscillation, J. Geophys. Res., 102, 929-945, 1997.

Gent, P. R., The heat budget of the TOGA-COARE domain in an ocean model, J. Geophys. Res., 96, 3323-3329, 1991.

Gill, A. E., Some simple solutions for heat induced tropical circulation, Q. J. R. Meteorol. Soc., 106, 447-462, 1980.

Hirst, A. C., Unstable and damped equatorial modes in simple coupled ocean-atmosphere models, J. Atmos. Sci., 43, 606-630, 1986.

Hirst, A. C., Slow instabilities in tropical ocean basin-global atmosphere models, J. Atmos. Sci., 45, 830-852, 1988.

Horel, J. D., and J. M. Wallace, Planetary scale atmospheric phenomena associated with the Southern Oscillation, Mon. Weather Rev., 109, 813-829, 1981.

Kessler, W. S., Observations of long Rossby waves in the northern tropical Pacific, J. Geophys. Res., 95, 5183-5219, 1990.

Knaff, J. A., Implications of summertime sea level pressure anomalies in the tropical Atlantic region, J. Clim., 10, 789-804, 1997.

Kundu, P. K., Ekman veering observed near the ocean bottom, J. Phys. Oceanogr., 6, 238-242, 1976.

Lindzen, R. S., and S. Nigam, On the role of sea-surface temperature gradients in forcing low-level winds and convergence in the tropics, J. Atmos. Sci., 44, 2418-2436, 1987.

Liu, W. T., A. Zhang, and J. K. B. Bishop, Evaporation and solar irradiance as regulators of sea surface temperature in annual and interannual changes, J. Geophys. Res., 99, 12,623-12,637, 1994.

Mapes, B. A., and R. A. Houze, Jr., Cloud clusters and superclusters 
over the oceanic warm pool, Mon. Weather Rev., 121, 1398-1415, 1993.

Mayer, D. A., and R. H. Weisberg, A description of COADS surface meteorological fields and the implied Sverdrup transports for the Atlantic Ocean from $30^{\circ} \mathrm{S}$ to $60^{\circ} \mathrm{N}, J$. Phys. Oceanogr., 23, 2201-2221, 1993.

Newman, M., and P. D. Sardeshmukh, A caveat concerning singular value decomposition, J. Clim., 8, 352-360, 1995.

North, G. R., T. L. Bell, and R. F. Cahalan, Sampling errors in the estimation of empirical orthogonal functions, Mon. Weather Rev., 110, 699-706, 1982.

Parsons, D., et al., The integrated sounding system: Description and preliminary observations from TOGA COARE, Bull. Am. Meteorol. Soc., 75, 553-567, 1994.

Philander, S. G. H., El Niño, La Niña, and the Southern Oscillation, 293 pp., Academic, San Diego, Calif., 1990.

Sciremammano, F., Jr., A suggestion for the presentation of correlations and their significance levels, J. Phys. Oceanogr., 9, 1273-1276, 1979.

Smith, T. M., R. W. Reynolds, R. E. Livezey, and D. C. Stokes, Reconstruction of historical sea surface temperatures using empirical orthogonal functions, J. Clim., 9, 1403-1420, 1996.

Suarez, M. J., and P. S. Schopf, A delayed action oscillator for ENSO, J. Atmos. Sci., 45, 3283-3287, 1988.

Wallace, J. M., T. P. Mitchell, and C. Deser, The influence of seasurface temperature on surface wind in the eastern equatorial $\mathbf{P a}$ cific: Seasonal and interannual variability, J. Clim., 2, 1492-1499, 1989.

Wallace, J. M., C. Smith, and C. S. Bretherton, Singular value decomposition of wintertime sea surface temperature and $500 \mathrm{mb}$ height anomalies, J. Clim., 5, 561-576, 1992.

Wang, C., and R. H. Weisberg, Equatorially trapped waves of a coupled ocean-atmosphere system, J. Phys. Oceanogr., 24, 1978-1998, 1994.

Wang, C., and R. H. Weisberg, Stability of equatorial modes in a simplified coupled ocean-atmosphere model, J. Clim., 9, 3132-3148, 1996
Weisberg, R. H., and C. Wang, A western Pacific oscillator paradigm for the El Nin̄o-Southern Oscillation, Geophys. Res. Lett., 24, 779$782,1997 \mathrm{a}$.

Weisberg, R. H., and C. Wang, Slow variability in the equatorial west-central Pacific in relation to ENSO, J. Clim., 10, 1998-2017, 1997b.

Webster, P. J., and R. Lukas, TOGA COARE: The coupled oceanatmosphere response experiment, Bull. Am. Meteorol. Soc., 73, 1377-1416, 1992.

White, W. B., S. E. Pazan, and M. Inoue, Hindcast/forecast of ENSO events based on redistribution of observed and model heat content in the western tropical Pacific: 1964-1986, J. Phys. Oceanogr., 17, 264-280, 1987.

White, W. B., Y. H. He, and S. E. Pazan, Redistribution of subsurface thermal structure during the onset of the 1982-83 and 1986-87 ENSO events and the 1984-85 anti-ENSO event, J. Phys. Oceanogr., 19, 1397-1406, 1989.

Woodruff, S. D., R. J. Slutz, R. L. Jenne, and P. M. Steurer, A comprehensive ocean-atmosphere data set, Bull. Am. Meteorol. Soc., 68, 1239-1250, 1987.

Zebiak, S. E., Diagnostic studies of Pacific surface winds, J. Clim., 3, 1016-1031, 1990

Zebiak, S. E., Air-sea interaction in the equatorial Atlantic region, J. Clim., 6, 1567-1586, 1993.

D. A. Mayer, Physical Oceanography Division, NOAA Atlantic Oceanographic and Meteorological Laboratory, 4301 Rickenbacker Causeway, Miami, FL 33149.

R. H. Weisberg, Department of Marine Science, University of South Florida, 140 7th Avenue South, St. Petersburg, FL 33701. (e-mail: weisberg@ocg6.marine.usf.edu)

(Received July 1, 1997; revised March 27, 1998; accepted April 29, 1998.) 